\title{
Thermography diagnostic of prototype habitat direct solar floor in northern Morocco
}

\author{
Z. Choulli ${ }^{{ }^{*}}$, A. El Bouardi ${ }^{1}$, H. Ezbakhe ${ }^{1}$, T. Ajzoul ${ }^{1}$, M. Lebied ${ }^{1}$ \\ ${ }^{1}$ Laboratory of Energy: Team Thermal, Solar Energy \& Environment \\ Abdelmalek Essaadi University, Faculty of Sciences, Tetouan, MOROCCO. \\ * Corresponding author: zchoulli@gmail.com
}

\section{Abstract:}

In this work, we present the thermography diagnostic of prototype habitat direct solar floor $7 \mathrm{~m}$ long, $4 \mathrm{~m}$ wide and $3 \mathrm{~m}$ high. It has a door and 6 windows, the door on the north side, 4 windows on the west side and two on the south side. This habitat is located in the northern area to the Faculty of Tetouan, Morocco.

The aim of the study is to evaluate the usefulness of infrared thermography as a technique for detecting the thermal performance in this prototype. To take the best results, the survey will be made at the beginning because there is no disturbance due to solar radiation and requires that the temperature difference between the inside and outside of the building is equal to about $10^{\circ} \mathrm{C}$.

\section{Introduction:}

Infrared thermography is being widely employed in some countries to determine the heat losses in urban buildings [1], as well as to predict structural failures [3] and problems relating to humidity [4]. In the present article, the application of thermographic surveys for habitat prototype direct solar floor.

\section{Theoretic basis:}

All materials have the capacity of absorbing infrared radiation, increasing its temperature. As well as all materials, whose temperature is above absolute zero emit infrared energy. Human eye is only able to receive the emissions belonging to the visible wavelength. Infrared radiation is located between visible and microwaves regions in the electromagnetic spectrum; comprising the wavelength from 0.75 to $10 \mu \mathrm{m}$. Infrared thermography is a technique that turns the emission pattern of an object into a visible image.

The thermographic cameras are used to measure the infrared radiation emitted by an object. Really the thermographic camera does not measure the temperature but the radiation of materials and by means of an interpolation in the Stefan- Boltzmann law (1) it is possible to get the temperature:

$$
E=\varepsilon \cdot \sigma \cdot T^{4}
$$

Where $\boldsymbol{E}$ is the energy of radiation $\left(\mathrm{W} / \mathrm{m}^{2}\right), \boldsymbol{T}$ is the temperature $(\mathrm{K}), \boldsymbol{\sigma}$ is the Stefan-Boltzmann constant (5.67 $\left.\times 10^{-8} \mathrm{~W} /\left(\mathrm{m}^{2} \mathrm{~K}^{4}\right)\right)$ and $\boldsymbol{\varepsilon}$ is the emissivity (non-dimensional). The radiation measured by the camera depends on the temperature of the object surface as well as on the emissivity of the material.

There are infrared cameras of short and long wavelength. For the purpose of this investigation, it is necessary to use a long wavelength camera. The advantages of the long wavelength camera are:

- It goes well at ambient temperatures;

- It is able to detect small temperature differences;

- It is less affected by solar reflection.

An object can reflect, transmit, and emit radiation. These three components of radiation are detected by infrared camera (see Fig. 1).

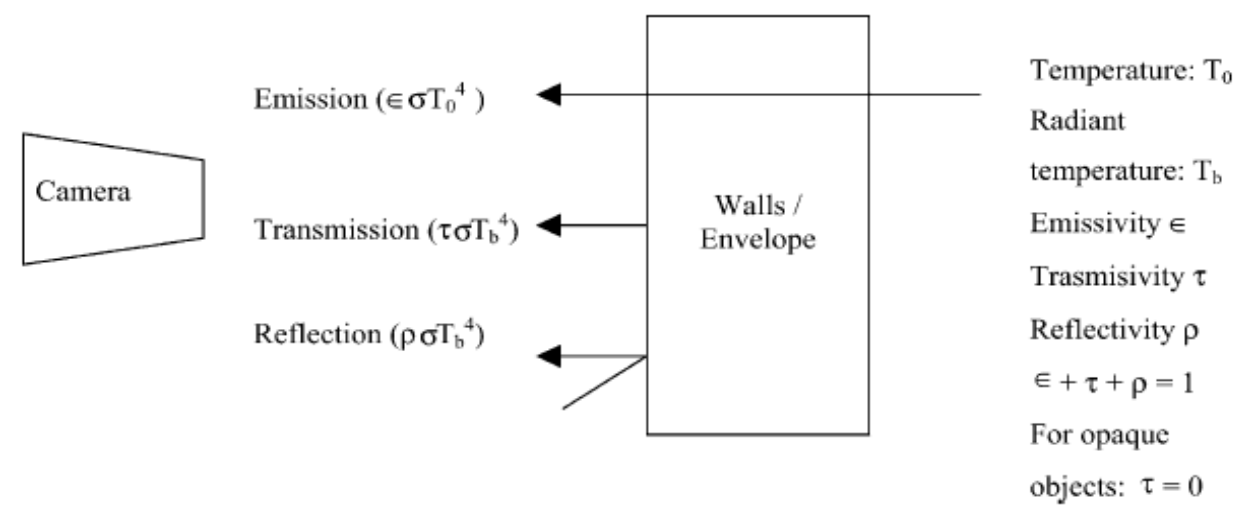

Fig. 1: Components of radiation measured by thermographic camera 


\section{Characteristics of the camera:}

The infrared camera used in this research is a FLIR B425 from FLIR SYSTEMS, and the software is FLIR Tools+ (from FLIR). The camera offers an outstanding solution for professional thermography conducting building inspections and energy declaration surveys. The technical specifications of the camera are:

Field of view/minimum focus distance: $25^{\circ} \times 19^{\circ} / 0.4 \mathrm{~m}$;

- $\quad$ Thermal sensitivity/NETD $<0.05^{\circ} \mathrm{C} @+30^{\circ} \mathrm{C}\left(+86^{\circ} \mathrm{F}\right) / 50 \mathrm{mK}$;

- Spatial resolution (IFOV): $1.36 \mathrm{mrad}$.

\section{The assessed buildings:}

The thermal performance of buildings was analyzed by the thermographic survey of habitat prototype direct solar floor, which is located in the north of Morocco Faculty of Tetouan, (see Fig. 2).

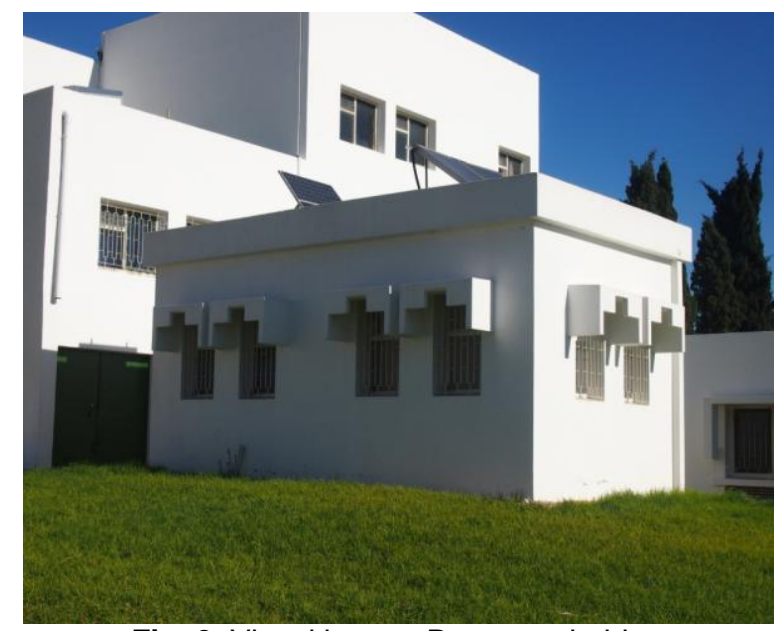

Fig. 2: Visual image: Prototype habitat direct solar floor

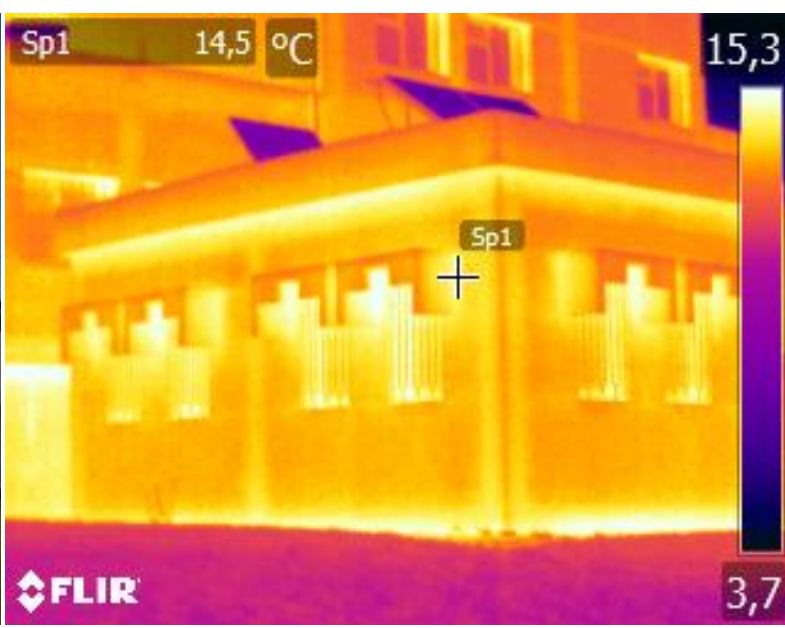

Fig. 3: thermal image: Prototype habitat direct solar floor

\section{Conclusions:}

In this study, the application of infrared thermography for the detection of the thermal behavior of the habitat. Thermographic survey was conducted in the home at dawn, in order to avoid errors that direct sunlight can be introduced into the results. The conclusions are:

- Infrared thermography provides a thermal image of the entire housing. It allows making a diagnosis of heat loss in the home.

- Infrared thermography allows detecting faults of thermal insulation, of openings and other points of heat losses.

\section{REFERENCES:}

[1] C.A. Balaras, A.A. Argiriou, Infrared thermography for building diagnostics, Energy and Buildings 34 (2002) 171-183.

[2] BS EN 13187:1999, Thermal Performance of Buildings-Qualitative Detection of Thermal Irregularities in Building Envelopes-Infrared Method, BSI, 1999.

[3] M.R. Clark, D.M. McCann, M.C. Forde, Application of infrared thermography to the non-destructive testing of concrete and masonry bridges, NDT \&E International 36 (2003) 265-275.

[4] V. De Luca, R.P. Mastroberti, A. Pallarda, Thermal-moisture testings and practical methods for re-use of rural buildings, in: Proceedings of the International Seminar of the Second Technical Section of C.I.G.R., Piacenza, June 20-21, 1996. 